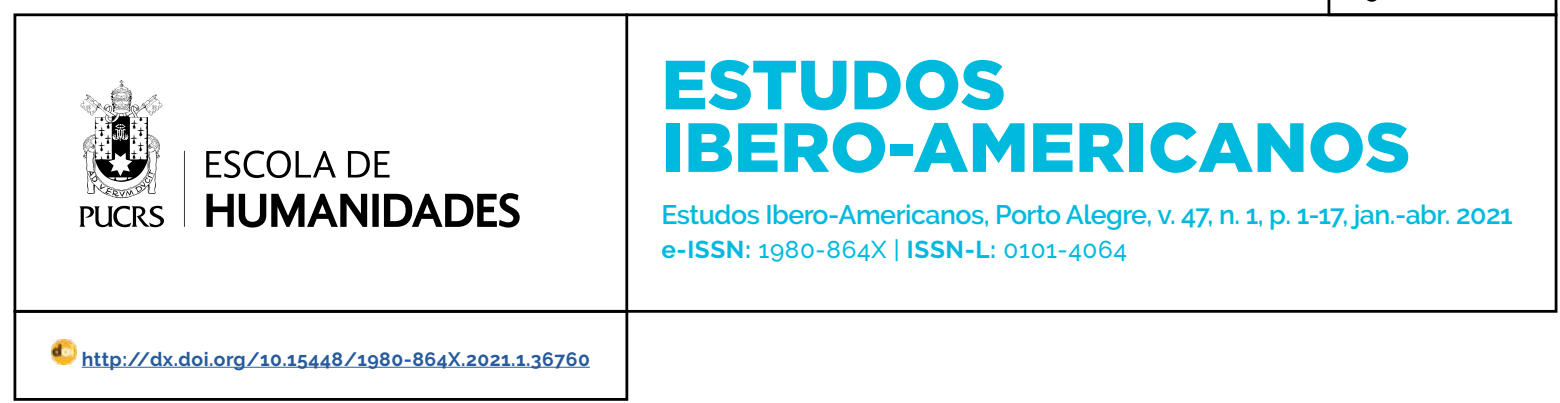

DOSSIÊ: HISTÓRIA DAS MULHERES, DAS RELAÇÕES DE GÊNERO E DAS SEXUALIDADES DISSIDENTES VOL. 47, N. 1

\title{
Modernidad, cultura y vanguardia feminista: Concha Méndez, una adelantada a su tiempo (Madrid, 1898-México, 1986)1.
}

\author{
Modernidade, cultura e vanguarda feminista: Concha Méndez, uma à frente de seu \\ tempo (Madrid, 1898-México, 1986) \\ Modernity, culture and feminist avant-garde: Concha Méndez, someone ahead of her \\ time (Madrid, 1898-México, 1986)
}

\section{Esmeralda Broullón \\ Acuña ${ }^{2}$ \\ orcid.org/0000-0002-0392-9128 esmeralda.broullon@csic.es}

Recebido em: $12 / 01 / 2020$ Aprovado em: 29/01/2021 Publicado em: 30/04/2021.

\section{(c) (i)}

Artigo está licenciado sob forma de uma licença Creative Commons Atribuição 4.0 Internacional.
Resumen: Las investigaciones acerca de las obras y las trayectorias proseguidas por un heterogéneo grupo de intelectuales, escritoras y profesionales exiliadas a causa de la Guerra Civil española, nos han reportado la oportunidad postergada de conocer sus creaciones y comprender las condiciones que desarrollaron sus proyectos en aras de un ansiado progreso y modernidad en clave de equidad. Estas experiencias emancipadoras, individuales o colectivas de las organizaciones femeninas y feministas, reflejan a su vez el entusiasmo político y socio-cultural en la España del primer tercio del siglo XX. Sin embargo, sus aspiraciones se vieron cercenadas tras la contienda y relegadas en el exilio a la sombra de sus cónyuges, familiares o compañeros en cuanto a destacadas figuras de la política, la cultura y distintas ramas del conocimiento. En este contexto, abordamos la trayectoria personal y, por ende, politica, de Concha Méndez: poeta, escritora, editora y divulgadora cultural en España y en América, que junto a Manuel Altolaguirre consagró su tiempo y dedicación a la difusión de su grupo intelectual. Palabras Clave: Cultura. Política. Narrativas. Género. Exilio. América.

Resumo: As investigações sobre os trabalhos e as trajetórias de um grupo heterogêneo de intelectuais, escritoras e profissionais exilados por causa da Guerra Civil Espanhola nos relataram a oportunidade adiada de conhecer suas criações e entender as condições que seus projetos desenvolveram para o bem de todos. Um progresso aguardado e modernidade em termos de eqüidade. Essas experiências emancipatórias, individuais ou coletivas de organizações femininas e feministas, refletem, por sua vez, o entusiasmo político e sociocultural da Espanha no primeiro terço do século XX. No entanto, suas aspirações foram cortadas após o concurso e relegadas ao exilio à sombra de seus cônjuges, parentes ou colegas em termos de figuras de destaque na política, cultura e diferentes ramos do conhecimento. Nesse contexto, abordamos a trajetória pessoal e política de Concha Méndez: poeta, escritora, editora e disseminadora cultural na Espanha e na América, que junto com Manuel Altolaguirre dedicaram seu tempo e dedicação à disseminação de seu grupo intelectual.

Palavras-chave: Cultura. Política. Narrativas. Gênero. Exilio. América.

Abstract: The investigations about the works and the trajectories pursued by a heterogeneous group of intellectuals, writers and professionals exiled because of the Spanish Civil War, have reported to us the postponed opportunity to know their creations and understand the conditions that their projects developed for the sake of a long-awaited progress and modernity in terms of equity. These

Este trabajo has sido desarrollado dentro del Programa I-Link/CSIC-2020 A20340. Acción para la promoción en Red de la Investigación, bajo el título: Arte, política y cultura. Mujeres y naciones en el marco de conflictos políticos claves del siglo XX y XXI con apoyo del Proyecto Intramural/CSIC 207749: Estudios americanos: política, ideología y estudios culturales II.

Escuela de Estudios Hispano-Americanos (EEHA), Sevilla, Epaña. 
emancipatory experiences, individual or collective of feminine and feminist organizations, reflect in turn the political and socio-cultural enthusiasm in Spain in the first third of the twentieth century. However, their aspirations were severed after the contest and relegated in exile in the shadow of their spouses, relatives or colleagues in terms of prominent figures in politics, culture and different branches of knowledge. In this context, we address the personal and, therefore, political trajectory of Concha Méndez: poet, writer, editor and cultural disseminator in Spain and in America, who along with Manuel Altolaguirre devoted his time and dedication to the dissemination of his intellectual group. Keywords: Culture. Politics. Narratives. Gender. Exile. America.

\section{A modo de introducción. Cultura política y vanguardia feminista en la Edad de Plata española ${ }^{3}$}

Las mujeres deben de ser feministas como los militares militaristas y como los reyes son monárquicos; porque, si no lo son, contradicen la razón de su existencia (MARTINNEZ SIERRA, 1930, p.17) ${ }^{4}$.

El feminismo español del primer tercio del siglo XX centró sus vindicaciones en la promoción socio educativa y laboral de las mujeres como vías de acceso a la igualdad y emancipación de estas. De primordial orientación republicana e interclasista (RAMOS, 2000, p.531), sus acciones no estuvieron circunscritas por el sufragismo que vertebraba el feminismo de los paises anglosajones. La cuestión femenina en España, heredera del feminismo librepensador de entre siglos, conquistó cuotas de equidad tras verse condicionada, en primer lugar, por una doble moral católica y, en segundo lugar, por un restrictivo aparato jurídico que arrastraba a las mujeres a situaciones de absoluto desamparo.

El nuevo marco humanista, acaecido durante el periodo de entreguerras, favoreció que las iniciativas colectivas e individuales de las féminas visibilizaran la histórica violencia recaída hacia las mismas por el pacto patriarcal interclasista que las confinaban a los márgenes de la sociedad (AMORÓS, 1990, p. 49). Asimismo, mientras que determinados estratos sociales se sustentaban sobre amplios privilegios, las mujeres se hallaban sometidas a unos constreñidos arquetipos, vinculados a la esfera de la domesticidad, cuya base moral y legal las concebía en cuanto a "ángeles del hogar" y las reducia a "sujetos menores" de edad. Bajo estas condiciones precisaban del beneplácito del esposo para tomar cualquier tipo de decisión. Ejemplo de ello era la obligada autorización del varón para comprar o vender propiedades; trabajar y administrar los beneficios de su trabajo, de sus propias rentas, etcétera. Autoritarismo y esencialismo que se mantuvieron en la representación legal del esposo durante la República, prolongando asi un mecanismo paternalista y condescendiente ante la "falta de preparación" de las mujeres; hecho exacerbado durante el largo invierno franquista. En cuanto al ámbito de las relaciones interpersonales, la continua vejación de la intimidad de las mujeres se mantenía sobre prácticas legitimadas por el Orden establecido. La moral sexual imperante las subordinaba al varón: sujeto activo del género humano frente al pasivo rol femenino. La sexualidad practicada fuera de la institución matrimonial conllevaba al estigma social de éstas y el adulterio se castigaba con medidas juridicas diferenciales para hombres y mujeres. La sexualidad y la procreación eran esferas que habia que salvaguardar; por ello, solo era legitimada en el marco de las relaciones conyugales. En consecuencia, el modelo de vida sexual extendido para las mujeres era la castidad y a esto se agregaban los fundamentos religiosos sustentados en la dicotomía biblica de mujeres buenas y mujeres malas respectivamente ${ }^{5}$. Un engranaje entre poder y sexualidad que más tarde sería revelado bajo el discurso del denominado feminismo radical.

\footnotetext{
3 Quiero dar las gracias a las compañeras del Club de Lectura del CDMZ-IAM de Sevilla y a su responsable, Aure Daza por la encomiable tarea de divulgación acerca de las obras y las trayectorias de figuras como la de Concha Méndez Cuesta.

4 Gregorio Martínez Sierra -empresario, editor, escritor y difusor de las ideas de la Institución Libre de Enseñanza- firmó en nombre de su mujer, Maria de la O Lejárraga (Maria Martinez Sierra. 1874-1974), textos, artículos periodisticos y conferencias de su autoria. El fragmento arriba citado se incluye en una de las compilaciones publicadas bajo el título: Cartas a las mujeres de España (1916).

5 Durante este mismo periodo, Margarita Nelken describió el dominio ejercido por parte de la religión y los varones hacia las mujeres en términos de esclavitud (NELKEN, 1919).
} 
El vigoroso proceso de modernización y de progreso social en base a la equidad, eclosionado durante el primer cuarto del siglo XX, contó con la participación activa de relevantes figuras -pertenecientes a una élite-, que trasgredieron las lindes del espacio público/privado y perpetraron luchas sociales con el fin de alcanzar derechos políticos. Entre estas despuntaron literatas, editoras, cofundadoras de revistas modernistas, profesionales, esposas de profesionales y, por supuesto, autodidactas ${ }^{6}$. No podriamos citar a todas ellas -entre las que se hicieron más visibles- en estas líneas, pero desde una perspectiva introductoria destacaríamos las aportaciones de Concepción Arenal; Emilia Pardo Bazán; Carmen de Burgos; María Lejárraga, Margarita Nelken o María Espinosa de los Monteros. Sus demandas giraron en torno a la preocupación de la formación, el acceso a la educación y las mejoras socio laborales como eje central del debate sobre la cuestión femenina en la España finisecular y el periodo de entreguerras, hasta que las vindicaciones, entre otras, por el sufragio femenino confrontaron las dos posiciones públicas lideradas por Clara Campoamor y Victoria Kent. La guerra civil catapultó no sólo sus persistentes reclamos, sino los proyectos colectivos e individualmente emprendidos que fueron amortizados con el exilio. Las redes creadas a lo largo de este proceso de experiencias emancipadoras les permitieron, a pesar de las fracturas devenidas en el seno de sus organizaciones, por un lado, amortiguar el desasosiego del transtierro y, por otro lado, buscar formas de manutención a través de la escritura o la traducción entre otras fórmulas de subsistencia.

Sólo por mencionar algunas de estas profesionales de diversas ramas, escritoras e intelectuales que se vieron abocadas al transtierro se hallaron en similar circunstancia: Concha Méndez, Ernestina Champourcin, Maria Teresa León, Zenobia Camprubí, Isabel de Oyorzabal, María de Maeztu, Matilde Huici, Elena Fortún, Victorina Durán, Carmen Eva Nelken, Constanza de la Mora, María Zambrano o las arriba citadas Maria Lejárraga, Margarita Nelken,
Victoria Kent y Clara Campoamor, entre otros testimonios aportados y obras silenciadas tras el exilio. El tesón y esfuerzo academicista realizado sobre el estudio de sus trayectorias y sus aportaciones no sólo han cuestionado la validez del canon literario o corroborado el progreso insuflado mediante sus vindicaciones, sino que nos ha transferido una dinámica imagen del paisaje politico y el pulso cultural de la España de entreguerras y sus aportaciones a la historiografía Iberoamericana. Asi que en el marco entusiasta pero también convulso ambiente político y cultural referido, abordaremos la trayectoria de la escritora Concha Méndez en relación a la consecución de su proyecto profesional. Es decir que, tomando como unidad de observación las esferas de lo público y lo privado, exploramos el singular itinerario de esta creadora y promotora de la historia cultural Iberoamericana. Su perseverante $y$, por veces, disperso trabajo sobre poesía, teatro, guiones cinematográficos, conferencias, ensayos, artículos periodísticos y traducciones -algunos de ellos inéditos o sin compilar, enmarcan la constricción del medio social e intelectual en el que tuvo que desarrollarse.

Dicho de otro modo, las acciones colectivas e individuales de estas mujeres, comprometidas por la modernidad irrumpieron en la escena pública durante un álgido periodo vanguardista, singularizado por una creatividad cultural de indole periodistica, divulgadora, editorial, artística, poética, teatral y cinematográfica. Esta vital proyección se vio enardecida entre 1926 y 1931 con la promulgación de la Il República (1931-1939). Como hipótesis de partida sostenemos que el correlativo proceso de progreso y modernidad se proyectó, instituyó arquetipos y difundió de modo sesgado, bajo contradicciones, las contribuciones de hombres y mujeres en las esferas de la cultura y las letras. A ello hay que añadir que el exilio trasatlántico catapultó a éstas con el olvido, junto a sus aspiraciones en el campo de la cultura, a la sombra de los intelectuales y ocupadas de la intendencia socio familiar en el nuevo escenario migratorio. Por ello y cuando los

\footnotetext{
6 Inexcusables referencias al marco de modernidad y vanguardia descrito se hallan, entre otras, en GÓMEZ-BLESA, 2019; KIRKPATRICK 2003: MAGNINI, 2001; CASTILLO, 2001.
} 
planes de igualdad en el territorio español son cuestionados desde la arena política, al tiempo que se desdibuja la fragilidad de los derechos alcanzados, uno de nuestros objetivos es el de contribuir, en base a la difusión de las autobiografías, las memorias y los testimonios intrahistóricos editados, al estudio no sólo de las obras de estas creadoras sino al análisis de sus trayectorias en relación a la historia cultural española, encaminadas a lograr mayores cotas de igualdad durante un periodo entusiasta pero hostil y de gran agitación social7. En definitiva, unos itinerarios personales y creativos estrechamente vinculados a sus proyectos políticos, corroborando una de las máximas del feminismo radical milleniano de cómo lo "personal es político" (MILLET, 1975). De este modo, además de recepcionar los progresistas planteamientos antecedidos durante aquellos años y hegemónicamente obstruidos, obtendremos una perspectiva de la fragilidad adherida a los derechos sociales y políticos, adquiridos bajo un pulso generacional, al mismo tiempo que permitirá avanzar en la divulgación de los trabajos y contribuciones realizadas por aquellas cuyo destino fue el exilio trasatlántico.

\section{Organizaciones femeninas y movimientos feministas en la Modernidad. De la razón ilustrada a la conquista de la ciudadanía (1926-1936).}

Entre las diversas organizaciones femeninas que contribuyeron al impulso de la modernidad de la sociedad y la cultura española, durante la llamada Edad de Plata (primer tercio del siglo XX), se hallaba el Lyceum Club femenino; corporación a la que perteneció la escritora madrileña, exiliada en México tras la guerra civil, Concha Méndez cuyo itinerario y obra poética aproximaremos en la segunda parte de este texto.
De corte elitista y bajo la inspiración del modelo británico y norteamericano, el Lyceum fue fundado en Madrid en 1926 por un grupo de mujeres de origen burgués entre las que se hallaban escritoras, creadoras, intelectuales, profesionales, asi como esposas de escritores, poetas o también profesionales destacados ${ }^{8}$. Es decir, estaba constituido únicamente por socias que habian recibido, al menos, una formación elemental y, por consiguiente, se hallaban "cultivadas" e interesadas en mantener un lugar de referencia propio donde organizar reuniones femeninas. Su finalidad era promover el desarrollo socio cultural y artístico que les negaba su propia condición de mujeres burguesas, cuyos valores trasgredieron al constituir esta colectividad. Si bien, entre las cofundadoras del Lyceum sería habitual su participación en diversas sociedades de corte feministas a un mismo tiempo; a excepción de Concha Méndez, cuyo desenvuelto carácter y autónoma personalidad la condujeron a su compromiso corporativo con el Lyceum y humanístico con el resto de las personas que se cruzarian en su larga trayectoria de poeta y editora-divulgadora exiliada.

La proyección intelectual a la que aspiraban las socias del Lyceum Club en el campo de las artes y las letras trascendía principalmente la limitada formación recibida. Una educación y socialización de "señoritas" condicionadas al esposo letrado y a la familia, a quienes se consagraban en su buen hacer. Sin embargo, un grupúsculo de éstas ya habia irrumpido en el escenario público de su época, no solo mediante el simbólico gesto de caminar por la calle ataviadas sin sombreros (BALLÓ, 2016) sino mediante el impulso de sus obras o proponiendo mejoras formativas y educativas que permitieran el acceso profesional restringido en las féminas. Esto último quiere decir

\footnotetext{
7 Un marco historiográfico sobre los avances y los retrocesos en la historia y cultura política de las mujeres en España, véase en RAMOS, 2014.

8 El Lyceum se fundó en Madrid en abril de 1926 en la Residencia de señoritas que la pedagoga María de Maeztu dirigía, principal promotora del proyecto junto a Victoria Kent como primera vicepresidenta. Las socias del Lyceum tuvieron que afrontar las sátiras publicadas en la prensa por sus acciones como también las presiones de su propio entorno que no veía apropiada esta iniciativa a la condición social de las mismas. Sobre El Lyceum Club de Madrid y el marco político cultural desarrollado, son inexcusables los trabajos de POZO, 1985, pp. 203-2012: FAGOAGA, 1985, pp. 78-179; 2002, pp. 145-167: HURTADO, 1999, pp. 23-36; MANGINI, 2006, pp. 125-140; MARINA y RODRIGUEZ, 2009; AGUILERA, 2011, pp. 65-90; MAINER, 2015, p.164.; EIROA, 2015, pp. 197-226.
} 
que, aunque el Lyceum se organizó en diversas secciones ${ }^{9}$, sus acciones estuvieron orientadas dentro del contexto político mencionado a alcanzar cotas de emancipación. De modo paralelo, al reducto privado que estaban confinadas, sus cofundadoras aspiraban a incorporarse en los movimientos de vanguardias y en las tertulias de los cafés a los que se hallaban excluidas. De ahi el enclave de una sede propia donde este modelo organizativo, junto a otros proyectos colectivos e individualmente emprendidos, contribuyera al proceso modernizador de la cultura, la política y la sociedad española de los años veinte y treinta del pasado siglo $X X$.

Sin ser un grupo homogéneo dentro de su orientación burguesa, la re-significación de los espacios dicotómicos, naturalizados en razón al sexo, y la apelación de cambios socio-políticos dotaron de contenido específico sus propuestas. Pero de manera que las demandas artísticas y formativas ocuparan el centro de sus experiencias emancipadoras. Bajo estas incursiones se desplazaron hacia un territorio atribuido a la masculinidad: el de la cultura, lo público, lo político. En consecuencia, actuaron más allá del constreñido espacio del salón de té que les había sido consignado por su condición tanto de género como de clase social. Buena parte de las promotoras del Lyceum, que solian actuar en red junto a otras corporaciones, ya procedian de un ambiente internacional y ello influiría en el pujante proceso modernizador de la sociedad cuyo proyecto político se materializaria en la República española. Así que las vanguardias, representadas en los varones, concurrieron ante el impulso culturalista de las socias del Lyceum Club, a pesar del rechazo perpetrado por amplios sectores de la sociedad. Su contribución ha sido dada a conocer y a pesar de la mala prensa a la que fueron sometidas, por sus actividades tanto sociales como artístico-culturales, persistieron en cercenar los valores adscritos a la esfera de la naturaleza y la domesticidad asignadas tradicionalmente a las mujeres frente a la proyección de la cultura y la política atribuida a los varones.

En este entusiasta periodo, hallamos a las fundadoras, socias o colaboradoras del Lyceum participando a modo de red en diversas organizaciones (FOLGUERA, 1988; LLONA, 1998; RAMOS, 2000; BLASCO, 2003; MORCILLO, 2012; SANFELIU, 2015). Y aunque no podríamos mencionar todas las sociedades fundadas durante estos años en la geografía española, citaremos, entre otras, aquellas agrupaciones feministas donde las socias del Lyceum destacaron por su contribución. Sirva de referencia la Asociación Femenina de Educación Cívica ("La Cívica", 1931-1936), fundada en el Ateneo de Madrid e impulsada por María Lejárraga -maestra, escritora y editora- junto a Clara Campoamor, una vez abandonada las filas del Lyceum Club, al considerar esta que sus líneas de actuación eran demasiado elitistas (MATILLA, 2002, p. 97; LUENGO, 2016, p.126, n.4). Dicho de otro modo, la diversidad de acciones en las que se hallaban comprometidas no solo las llevarían a trascender el reducto al que estaban consignadas, sino a defender unas vindicaciones de signo político para la consecución de la ciudadanía plena.

Otras promotoras del Lyceum como María de Maeztu, Clara Campoamor o Victoria Kent también participaron de manera muy activa y confederada junto a distintas corporaciones que emergieron en el panorama español durante estos vigorosos años, tal como fue la Asociación Nacional de Mujeres Españolas (ANME, 1918-1936), fundada por María Espinosa de los Monteros en su propio domicilio de la calle Barquillo de Madrid y por Isabel de Oyorzabal. La AMNE, de afiliación conservadora y de corte sufragista se posicionó en defensa de los derechos civicos. Asimismo, fue una de las primeras asociaciones que contó, además de una larga trayectoria, con un periódico propio -"Mundo Femenino" (1921-1936) - dentro de la diversa prensa asociativa femenina de la época y divulgadora de dispares contenidos que iban desde la ornamentación femenina a la disciplina de contención obrerista o los ansiados valores emancipatorios. Su presidenta,

\footnotetext{
9 La organización del Lyceum se articuló en torno a siete secciones o líneas de actuación: social; música; artes plásticas e industriales: literatura; ciencias sociales; internacional y una sección especial Iberoamericana.
} 
Maria Espinosa, y también cofundadora más tarde del Lyceum, presidió el Consejo Supremo Feminista de España (1918) en el que se articulaba el feminismo español, puesto que el Consejo agrupaba, además de la propia ANME, a otras cuatro asociaciones feministas en los albores de la República: La Mujer del Porvenir; La Progresiva Femenina de Barcelona, La Liga Española para el Progreso de la Mujer y la Sociedad Concepción Arenal de Valencia. Estas primeras organizaciones de distintos signos fueron incorporando entre la histórica defensa por el derecho a la educación -como ya venían haciendo a título individual sus integrantes- defensas políticas contra la amplia discriminación que sufrian las mujeres ${ }^{10}$.

Además de la AMNE que adoptó una notable relevancia durante el periodo de entreguerras ${ }^{11}$, otros grupúsculos se forjaron en diferentes enclaves urbanos de la geografía española. En este mismo contexto despuntó, entre otras, la socialista Unión de Mujeres de España (UME, 1919) fundada en Madrid por la mencionada socia del Lyceum: María Lejárrega junto a Lily R. de Cabrera Schenrinch. Asimismo, profesionales, escritoras y editoras como la misma Lejárrega ya participaban en movimientos internacionalistas, desde la primera década del siglo $X X$, puesto que esta también encabezó en 1912 -en un mar revuelto entre organizaciones femeninas de distinto signo-, la secretaría española de la Alianza Internacional del Sufragio de la Mujer -IWSA, International Women's Suffrage Alliance-.

Durante los años veinte otra socia del Lyceum presidió una asociación feminista de orientación pacifista. Este era el caso de Isabel de Oyorzabal, que presidió la Liga Femenina Española por la Paz (1930). Al mismo tiempo, Oyorzabal trabajó de manera activa en la Sección Española de la organización Mundial de Mujeres contra la Guerra y el Fascismo y ulterior agrupación de Mujeres Antifascistas (AMA) tras el advenimiento la Guerra Civil Española (RODRIGO, 1998, p. 68).

De modo paralelo al mencionado asociacionismo de corte progresista liberal, surgieron durante estos mismos años asociaciones femeninas católicas que, bajo un compromiso social y religioso, también apostillaban por la formación y la mejora de las condiciones laborales en la que se hallaban las mujeres (BLASCO, 2003). Sin embargo, rechazaban la participación femenina en las esferas públicas y, por extensión, en lo político. Esta representación se materializó de manera destacada en La Acción Católica de la Mujer (ACM, 1919) que llegó a formar parte de una estructura supranacional mediante la Unión Internacional de Ligas Católicas Femeninas (UILCF, Bruselas 1910). En 1934 la ACM se fusionó junto a otra corporación cristiana española -La Unión de Damas del Sagrado Corazón- para constituir La Confederación de Mujeres Católicas de España. Resta decir que su discurso central giró en torno a la natural adhesión de la mujer en las relaciones tradicionales y en la esfera de lo domestico y privado.

Sin haber eclosionado un movimiento político al estilo británico o norteamericano, de centralidad sufragista, la permeable presencia de estas colectividades femeninas y feministas -católica o laicas- tanto en la retaguardia como en la vanguardia de esos años, adquieren el punto de inflexión en un momento clave que proporcionarán la oportunidad de experiencias emancipadoras en sus participantes. Así, la igualdad civil, política y juridica plasmada en sus vindicaciones formaron parte del programa de la II República y quedó

\footnotetext{
10 Entre las pioneras organizaciones femeninas de comienzos del Siglo XX, destacaron La Junta de Damas de Unión Iberoamericana de Madrid (1906) que se hallaba constituida por mujeres católicas de clase acomodada. Sin la reparación de los derechos políticos, sus demandas estuvieron centradas en mejoras de las condiciones femeninas mediante la educación y en las condiciones de trabajo, pero sin relegarla de los valores adscritos a la familia en vinculación a la sociedad. Como sería habitual las organizaciones contaban con órganos de expresión y La Junta de Damas promovió la Revista "La ilustración de la Mujer". En cuanto al orden de ámbito sufragista, la primera movilización de carácter interclasista, a favor del voto femenino, fue liderada en 1921 por La Cruzada de Mujeres, dirigida por Carmen de Burgos que mediante esta acción promovió la opinión pública acerca del sufragismo. Mientras que, en Cataluña, Carmen Karr, defensora igualmente del sufragio femenino y promotora de la revista "Feminal" entre 1907 y 1917, impulsó y presidió el Comité Femenino Pacifista de Catalunya (1915). Acción Femenina (1921) y Llar (Hogar, 1913) como primera residencia propiamente dicha para la ampliación de estudios de profesoras, como de estudiantes. Para una revisión del sufragismo en España véase, entre otros, MORCILLO GÓMEZ, 2012, pp.60-65 (62); FAGOGA, 1985; CAPMANY, 1970, pp.102-103.

${ }_{11}$ De la AMNE surgió La Agrupación Juventud Universitaria Femenina (JUF, 1920) donde Victoria Kent fue representante en varios de sus encuentros de carácter nacional e internacional.
} 
forjado en la reforma de los Códigos Civil de 1889 y Penal de 1879. A través de la Constitución republicana se logró el sufragio femenino ${ }^{12}$, aunque las mujeres siguieron discriminadas en el terreno laboral y en el ámbito moral (Ramos, 2000, p. 537), mientras que progresistas reformas se aplicaron al sistema educativo, a modo de coeducación, y a la institución familiar atenuando las restrictivas esferas de la sexualidad.

Como es sabido estos avances fueron interrumpidos tras la contienda y después de una permanente resistencia contra corrientes fascistas $^{13}$. El progreso en materia de equidad, legislado durante la República e impulsado mediante las acciones de las distintas agrupaciones, fue catapultado tras la victoria franquista. Por su parte, la Sección Femenina como órgano de la Falange española, tomó protagonismo y ocupo el centro de la cultura política femenina bajo los tradicionales valores de domesticidad, paternalismo y condescendencia. Fundamentos esencialistas y biologicista justificaron el desolador retroceso en derechos de una generación que habría combatido la discriminación, a pesar de los heterogéneos intereses y fundamentos ideológicos. La realidad es que fueron relegadas de los cargos públicos y de las responsabilidades asumidas con sus vindicaciones. A cambio se impuso el adoctrinamiento en el ideal de "la perfecta casada" y el sometimiento a las nuevas politicas natalistas, dejando atrás la coeducación y el sufragio. Así fue igualmente anulado el matrimonio civil, el divorcio y perseguida la participación sindical y política: el cielo y la tierra, y por extensión el ho- gar y el confesionario se alzaron en los espacios habitados de la nueva mujer en España.

\section{Entre las modernas de Madrid: Concha} Méndez, una adelantada a su tiempo.

\begin{abstract}
¿Ésa? iEsplendido ejemplar! Ésa es Concha, Conchita. Esta muchacha, con ese pergeño de chica burguesa, modosa y buenísima, era un torpedo [...] ¿En alguna ráfaga amorosa? No. Si es una monja alférez. Casta y guerrillera [...] Y ahora, Concha, ¿adónde vamos y de dónde venimos? Me marcho a África, vengo de América y he pasado por Oceania (GIMÉNEZ
\end{abstract}

CABALLERO, 1932).

La cultura y el pensamiento en claves de equidad y como vías emancipadoras en el contexto político de la España del primer cuarto de siglo, constituyen unidades de análisis en el presente texto. Desde esta perspectiva, la fundación en 1926 del Lyceum Club femenino, promovido por María de Maeztu en la sede de la Residencia de señoritas que esta misma dirigía, coincidió con la vigorosa actividad de la Residencia de estudiantes para hombres bajo el impulso de la Generación del 27. Asimismo, tres años antes de la puesta en marcha del Lyceum, Ortega y Gasset habia fundado la Revista de Occidente (1923), donde solo Rosa Chacel y María Zambrano, exiliadas más tarde a causa de la contienda, colaboraron en la misma (QUANCE, 2001, p.107). En relación al postergamiento de la actividad profesional y promoción cultural femenina, Concha Méndez comprometida socia del Lyceum madrileño, destacó por su fecunda aportación al género de las

\footnotetext{
12 En materia de derechos políticos el Estatuto Municipal de 8 de marzo del 1924 -bajo la dictadura de Miguel Primo de Rivera (1923-1930)concedió el voto a la mujer, en calidad de cabeza de familia, tal como recoge la exposición del Decreto-Ley sobre Organización y Administración Municipal que fue refrendada el 12 de abril de 1924. Sólo a través de la Constitución republicana se alcanzó el sufragio femenino, mientras promovió progresistas reformas al sistema educativo y a la institución familiar junto a amplias esferas como la sexualidad.

13 Durante los años treinta y especialmente en el último periodo de la República, las mujeres de distintas adscripciones culturales e ideológicas persistieron organizándose -como respuesta al fascismo- en razón a la propia discriminación, en cuanto a mujeres, dentro del heterogeneidad marco de sus intereses. De ahi los diversos planteamientos estratégicos y la disposición en distintos frentes para la consecución de la igualdad. Entre las corporaciones más relevantes de este convulso panorama destacó la Agrupación de Mujeres Antifascistas (AMA), fundada en 1933 por mujeres republicanas -laicas y católicas-, comunistas y socialistas. La AMA contó con un órgano propio de expresión que era la revista "Mujeres" y se constituyó como la organización española de mujeres "oficialista" por su estrecha cooperación con el gobierno Republicano. Desde un ámbito libertario, fue creada la agrupación Mujeres Libres en abril 1936 que de igual modo contó con una revista homónima. Mientras que la Unión de Muchachas registrada en 1937 se organizó como representante de Juventud Unificada Socialista cuya revista adoptó el mismo rótulo de "Muchachas". De similar orientación, El Secretariado Femenino del POUM (SFPOUM) se creó en septiembre de 1936 y, al igual que las anteriores señaladas, conto con un programa más revolucionario a favor de la mujer. Sion embargo, los avances en materia de equidad legislados durante la República y las experiencias puestas en marcha por las distintas corporaciones femeninas fueron catapultados tras la victoria franquista. Por su parte, la Sección Femenina como órgano de la Falange española tomó protagonismo en la contienda y ocupo el centro de la cultura politica femenina replegada de nuevo hacia valores de domesticidad durante el franquismo. Al respecto sirva de referencia, NASH, 1981; BIZCARRONDO, 1984, pp. 137-159; RAMOS, 2002, p. 530; MARCOS DEL OLMO Y SERRANO GARCIA (eds.), 2012, pp. 159-181; AGUADO Y ORTEGA (coord.), 2011; MARTiNEZ (dir.), 2000, p.139.
} 
artes y las letras, al mismo tiempo que revitalizó el panorama cultural español de los años treinta mediante su labor editorial y divulgadora ${ }^{14}$. En este sentido, solo Concha Méndez y Carmen Conde entregaron su tiempo y su conocimiento a las tareas impresoras y editoriales, a la sombra de sus maridos poetas e impresores: Manuel Altolaguirre y Antonio Oliver Belmás (QUANCE, 2001, p.110).

El acceso de las mujeres a la esfera artístico cultural se sustentaba, por lo regular, bien por sus capacidades seductoras o bien por el empuje del esposo o colega hacia el parnaso intelectual. Junto a otras artistas, intelectuales o profesionales de distintas ramas del conocimiento, Concha Méndez fue creadora de una desigual, pero nada desdeñable obra. En su caso, ejerció de traductora y vendedora editorial cuando tuvo que buscar el sustento como transterrada fuera de España. La junto a unas siempre inquietas facultades creativas y emprendedoras, la harian hasta cierto punto inclasificable. Bajo el ímpetu de alcanzar la soberania personaly la independencia, entre las voces poéticas, su escritura dio un giro hacia la lirica en clave de modernidad. Justo en el momento en que su narrativa alcanzó un desarrollo creativo en los años treinta y se reafirmó en su carácter emancipador, fue promulgada la República española que prometía implementar un proyecto político en clave de equidad. En ese momento y entre "las modernas de Madrid" se hallaba Concha Méndez de regreso por Inglaterra y Argentina. Desde su atildada posición transgredió el constructo arquetípico de feminidad en la clase acomodada y, sin lugar a dudas, rebatió el lastre cientificista sobre la menor dotación de capacidades en las mujeres ${ }^{15}$ : tesis abanderada por Ortega y Marañón, cuyas sus esposas también fueron socias del Lyceum Club. Pero, aun asi, la escritora madrileña fue significada en su medio intelectual como novia, esposa, compañera y amiga de reconocidos escritores y artistas, entre los que destacaron Luis Buñuel; Manuel Altolaguirre; Federico García Lorca; Rafael Alberti o Luis Cernuda a quien dio cobijo en su propia casa hasta los últimos dias del poeta sevillano.

Entre las diversas organizaciones femeninas desplegadas en la sociedad española del primer cuarto del siglo XX hemos reparado en el Lyceum Club de Madrid, puesto que fue la agrupación a la que perteneció Concha Méndez: única a la que estuvo adscrita, a diferencia de muchas de sus coetáneas, teniendo en cuenta su fuerte carácter independiente. En elámbito intelectual desarrolló, entre otros géneros, una nada desdeñable obra poética en concordancia a su trayectoria vital, a la vez que trasgredió el constructo de feminidad atribuido a las mujeres de su clase social. Bajo el desobediente signo del sinsombrerismo de la época ${ }^{16}$ y del ambiente burgués, que no permitía a las jóvenes salir solas, transitó -junto con la pintora Maruja Mallo quien la retrato en su juventud- por los barrios de la capital como por los cafés predestinados a los intelectuales. A un mismo tiempo participaba de las acciones artístico culturales organizadas en el Lyceum Club femenino en cuya sede logro representar una de sus obras teatrales, ya que estas piezas nunca fueron estrenadas en ningún teatro de la capital $(\text { NIEVA, 2004, p. 73) })^{17}$. Tanto su poesía como su legado memorialistico y documental transfieren la imagen de una mujer dotada de fuerte personalidad y de apariencia enérgica: positiva, algo excéntrica e influenciada tanto por el surrealismo de la época como por su prevalencia onírica. De vital temperamento y arrolladora generosidad, su espontaneidad la hacian incrédula frente a los

14 Concha Méndez contribuyó junto a su marido a la edición de relevantes revistas como Poesía: Héroe; 1616 o Caballo verde para la poesía dirigido por Pablo Neruda y a quien el matrimonio ofreció esta representación. El domicilio de la pareja situada en la calle Viriato de Madrid se convirtió en el espacio de encuentro de la Generación del 27, así como el lugar donde recibian, impulsaban y difundian los trabajos de sus contemporáneos hasta llegar la fratricida guerra. Su aventurada empresa editorial prosiguió con ellos durante el exilio. Entre las primeras investigaciones que destacan la contribución de Concha Méndez se hallan BELLVER, $1993 ; 1997 ; 2001$.

15 La nueva Constitución junto con la reforma de los Códigos recogerian las capacidades y los derechos femeninos. Una referencia a ello puede ser consultada en NELKEN, 1931, p.5; NÚÑEZ, 1998, pp. 393-446; AGUADO y RAMOS, 2002; RAMOS, (ed.), 2006; RODIGO MORA, 2016.

16 Sobre la significación de liberarse del sombrero y su alcance se pronunció Gómez de la Serna en un relevante artículo para el periódico El Sol. GÓMEZ DE LA SERNA, 1930, p. 10

${ }_{17} \quad$ "El ángel cartero", representación infantil que logró ser estrenada en la Sede del Lyceum el día de Reyes de 1929 y cuya escenografia corrió a cargo de su amiga y correligionaria Maruja Mallo. Para una aproximación de los registros teatrales de la escritora madrileña véase, NIEVA DE LA PAZ, 2004, pp.72-76; MUÑOZ CALIZ, 2018, pp.187-200. 
restrictivos códigos impuestos o ante la podredumbre humana que hubo de soportar desde su condición de mujer y transterrada.

Tras las expectativas barajadas de progreso -intelectual, laboral, político y reformador- que antecede al advenimiento de la República, apesadumbra las consecuencias derivadas del exilio, exterior e interior, y el particular ensañamiento hacia las féminas una vez revocadas sus vindicaciones y sus derechos alcanzados. En este sentido, Concha Méndez no promulgaba las teorias feministas; sin embargo, la certeza de su soberanía muestra a una mujer moderna -pronunciándose y actuando a favor de la equidad que es en resumen aquello que el feminismo procura-, cuya proyección acabo cercenada al igual que ocurriria con las mujeres del medio intelectual traido a colación. Esto último quiere decir que la aproximación a su obra permitirá comprender algunas claves de la realidad política y de los roles de género asignados a esta generación. De hecho, a través de su imaginario poético, la escritora madrileña trató de trascender una permanente autoridad patriarcal que -desde joven hasta su plena madurez- la relegaría a las sombras del grupo que ella misma abrigó y promocionó en su papel de editora junto a Manuel Altolaguirre. En definitiva, para ser "tomada en serio, salvo como portavoz de la vida de los otros" (ULACIA ALTOLAGUIRRE, 2018, p. 20). El firme propósito de romper con los cánones requeridos de musa o ángel del hogar en las féminas de la clase media y acomodada, junto a la convicción de su vocación creativa, la hacen pionera en la conquista silenciosa de un feminismo cuyas teorias no parecía comulgar de modo directo, pero sobre el que se pronunciaría con honestidad. La acérrima confianza en sí misma y su pronta toma de conciencia sobre las desigualdades entre hombres y mujeres, y entre clases sociales, la llevaron a superar obstáculos con la misma deportividad practicada en su mocedad. En las memorias dictadas a su nieta relata diversas afrentas familiares, entre ellas su temprana discrepancia sobre que "las niñas no son nada" cuando le preguntaron qué quería ser de mayor, a lo que respondió: "capitana de barco" (ULACIA ALTOLAGUIRRE, 2018, p. 24) ${ }^{18}$. En esta línea configuraría el perfil de una mujer con aires de rotunda modernidad que, a modo de reinventarse ante la fragilidad de los hechos sobrevenidos, logró trascender tanto la limitada "buena educación" recibida a una minoría como los modelos de feminidad impuestos que no hacian más que coartar su independencia. Los episodios históricos que la asistieron a lo largo del siglo XX, tanto en España como en el exilio, la relegaron como poeta a la sombra pero hasta en sus márgenes reafirmó una autónoma identidad personal y profesional.

\section{De la voluntad emancipadora al exilio trasatlántico. Una aproximación a la obra poética y la trayectoria de Concha Méndez (Madrid, 1898-México, 1986)}

Yo no sé si soy feminista o no -afirmó en-
tonces-. Toda idea que encierra un sentido
colectivo me repugna moralmente. Yo soy:
individualidad, personalidad. Ahora bien, en
cuestión de derechos también pido igualdad
ante la ley. O lo que es lo mismo: pasar de ca-
lidad de cosa a calidad de persona, que es lo
menos que se puede pedir ya en esta época
(VALANDER, 2001, p.150) ${ }^{19}$.

Concha Méndez irrumpió de manera autodidacta en el campo de las letras. Influenciada en sus inicios por la sonoridad de los poetas andalu-

\footnotetext{
18 La reedición de estas memorias, dentro de las líneas de la editorial Renacimiento en 2018 y la Biblioteca del Exilio, nos permite acceder a la intrahistoria de este heterogéneo y plural grupo de intelectuales, pero sobre todo seguir estudiando la obra y la trayectoria de la colectividad más invisibilizada que, igual que sus compañeros, conocieron el exilio. Al mismo tiempo es una valiosa contribución de intrahistoria y oralidad acerca del exilio español: una tarea acometida por su nieta. Paloma Ulacia Altolaguirre, que selecciona y da forma a la singular historia de vida cuyo marco referencial es el ambiente artístico-cultural de su época, tanto en España como en el exilio Asimismo, ya fue declarada en 1988 finalista del Premio Comillas de Historia, Biografía y Memorias de Tusquets Editores y en 1990 fueron publicadas, por primera vez, en la editorial Mondadori. Si el texto emana de esta experiencia, así debemos comprender la selectiva prevalencia por los detalles autobiográficos y memorialisticos registrados. De hecho, Concha Méndez refuerza, mediante esta técnica, su conciencia de identidad y por ello estas memorias "habladas" apenas dejan espacio para la transferencia de su propia obra que, no obstante, es sucintamente introducida en conexión a algunos de los hechos mencionados. ULACIA ALTOLAGUIRRE, 2018.

19 Entrevista realizada en España a Concha Méndez, por ITURRALDE, 1928
} 
ces -en especial, Rafael Alberti y Federico Garcia Lorca que la introdujeron en la lírica-, compuso sin una encauzada formación acrisolados versos que la llevaron a superar la estereotipada estética sentimentalista adscrita a la lírica de las "poetisas"20: Las luces / beben la niebla. / Luciérnagas de bocina / se deslizan / por la tierra. / Bajo la sombra nocturna, / se durmieron / las veletas. / Por el hondo firmamento / se perdieron / las estrellas. (MENDEZ CUESTA, 1976, p. 22) ${ }^{21} \mathrm{Y}$ entre decantarse por la tradición o la modernidad, acabó asentando una personal voz reflexiva cuya impronta memorialista dio abrigo al peso de la soledad y de los dramas acaecidos tras la guerra civil española: Soledad, yo te siento la mejor compañera; / en tus brazos me apoyo para ser cuanto quiero./ iAmparada en tu fuerza, puedo ser yo esa fuerza / que me lleve algún día a habitar un lucero! (MÉNDEZ CUESTA, 1976, p. 99)22

A lo largo de su trayectoria vital que se halla vinculada a su desarrollo creativo, podemos establecer grosso modo tres etapas. Entre la primera (1926-1930) y la segunda etapa (19321944) acabaría prevaleciendo la poesía en una vasta obra marcadamente autobiográfica. Su diverso y, por veces, disperso desarrollo creativo fue compaginado con los compromisos editoriales a los que se entregó junto a Manuel Altolaguirre. Comenzó explorando sus primeros poemas bajo la influencia de las vanguardias de la época, así que oscilante entre el clasicismo y la modernidad publicó sus dos primeros libros de poemas, titulados Inquietudes (1926) del que pronto se desdijo y Surtidor (1928), donde la autora mantuvo la atribución vanguardista de los poetas de su generación, aunque sin abandonar la influencia juanramoniana. De manera que sus primeras incursiones líricas se enmarcaron entre la tradición y la modernidad, al tiempo que el universo de las telecomunicaciones asomaba en sus versos bajo la impetuosa alacridad de los años veinte: Mi frente, / junto al cristal del tranvía. / Tarde de azogue. / Domingo. / Cruza un húsar de Pavia /. Las plazoletas de plata. / Las modernas avenidas. /Suplantaciones de sombras / por la sombra de este día. / Paisaje urbano. / Mi frente, I junto al cristal del tranvía (MÉNDEZ CUESTA, 1995. p. 165$)^{23}$. Dicho de otro modo, vitalismo y romanticismo, en una aparente contradicción lírica, decantaron la voz poética de los versos de estos luminosos años.

Respecto a la esfera privada y familiar que duramente la reprendió solo por haber asistido a una conferencia en la Universidad, Concha Méndez logró emanciparse bajo su confirmación narrativa. De todos sus proyectos emergía una emprendedora aventurera y, como tal, decidió viajar sola fuera de España: perseguir la independencia a través del viaje pareciera formar parte de un mismo proceso. De esta trotamunda experiencia extrajo que tenía sobrada capacidad para mantenerse a sí misma; si bien su entorno intelectual le sirvió obviamente para sustentar tan atrevido periplo por Europa y América.

Sin compañia alguna realizó un primer viaje a la capital británica en 1929, donde permaneció seis meses con el objetivo de ilustrarse en los estudios cinematográficos de Elstree 24 . Tras su regreso emprendió un nuevo viaje trasatlántico con destino al Río de la Plata donde recaló el mismo día de Nochebuena. Este itinerario transcontinental adquirió un punto de inflexión en la trayectoria personal y profesional de Concha Méndez, ya que durante el viaje austral la escritora madrileña

\footnotetext{
20 Adscritas tradicionalmente a un natural esencialismo femenino en contradicción a la modernidad y la universalidad como aspiración vanguardista de este periodo; ya que la voz de las denominadas "poetisas", aun teniendo una aceptada acogida, mantenian una orientación más personalista respecto a las creaciones de sus colegas poetas. Pero, en definitiva, unas experiencias desarrolladas bajo trayectorias vitales y artísticas diferenciales entre mujeres y varones. Durante esta vigorosa época La Gaceta Literaria calificaba de "novedosa" y "seductora" las creaciones de las poetisas de la vanguardia y, en virtud a estas acepciones, sus contribuciones fueron consignadas en dos secciones bajo los rótulos de "Mapa en Rosa", donde fueron publicados los versos de Concha Méndez, y "Mapa en Carmín". Al respecto es ilustrativa esta observación en QUANCE, p.107.

${ }_{21}$ "Nocturno de ciudad". Publicado originariamente, en MÉNDEZ CUESTA, 1928.

22 "Soledad". Publicado originariamente, en MÉNDEZ CUESTA, 1944.

23 "Paisaje". Publicado originariamente, en MÉNDEZ CUESTA, 1928.

24 En la misma fecha de su viaje a Londres se hallaba rodando en España una película basada en un guion que Concha Méndez, fascinada por el séptimo arte, había escrito en 1927: "Historia de un taxi", grabado por Carlos Emilio Nazari. Véase, PÉREZ DE AYALA, 1927. pp. 115-128; UTRERA, 2000
} 
reafirmó a un mismo tiempo su vocación creativa y su capacidad emancipadora. En los dieciocho meses que duró la estancia porteña (1929-1931), además de distenderse mediante su vitalista sociabilidad, escribió varias obras de teatro (NIEVA DE LA PAZ, 1993; 2010; 2013.) y colaboró con artículos en revistas y en prensa (VALANDER, 2001, pp.149-163). Asimismo, publicó su tercer libro de poesías avezado por los aires de modernidad que la acompañaron durante ese trayecto. Obra que fue concebida por su autora como un "libro de viajes" y de "amistades": Canciones de Mar y Tierra (1930), con prólogo de Consuelo Berges e ilustraciones de Norah Borges, fue muy bien recibida por parte de la prensa. Por entonces Concha Méndez trataría de afianzarse como poeta a la última vanguardia, en un ingenuo pulso de aproximación a las creaciones de sus compañeros poetas y en un medio escindido entre las esferas de la cultura adscrita a los poetas y la naturaleza a las poetisas: Que me pongan en la frente / una condecoración. /Y me nombren capitana / de una nave sin timón (MÉNDEZ CUESTA, 1930)25. Desde esa frontera trascendió las seductoras y erotizadas voces en aras de una identidad personal -muy singularizada por su reinvención creadora-, dentro del parnaso cultural de su generación.

Su vuelta a España en 1931 no solo coincidió con el proyecto reformista de la II República sino con la formalización de su relación con Manuel Altolaguirre en 1932. Tal como alude en sus memorias, el poeta y editor ya le habría solicitado en matrimonio antes de su periplo trasatlántico. A partir de este momento se inició un productivo y creativo periodo para ambos, y aunque sus primeras composiciones ya vieron la luz antes de conocer al poeta malagueño, su fase más álgida se situaría entre 1932 y 1944 en un periodo de madurez, intelectual y personal, en consonancia a sus experiencias tanto en las esferas públicas como privadas que, en realidad, apenas mantendría escindidas. Y no solo sufragó tras su retorno por Argentina a la rotativa Altolaguirre-Méndez, sino que intervino en la impresión y divulgación de imponderables colecciones de libros o revistas a favor de su propia generación en cuyas antologias no habria sido incluida. Al igual que les ocurriera a sus coetáneas, el olvido intelectual acompañaría a esta socia del Lyceum Club, tal como se evidencia en la postergación de la visibilidad de su obra o en el desconocimiento, hasta hace bien poco, de su aporte al ámbito editorial y de las letras en España y América.

Llegada a una segunda etapa que transitará durante más de una década (1932-1944), su voz poética exploró otros universos y al mismo tiempo que el vanguardismo comenzaba a ser relegado por una humanización del arte, la escritora sondeaba en sus estrofas un diálogo entre armónico e igualitario en su relación con la sociedad y el género humano. Asi se constata en un poema que forma parte de su cuarta obra Vida a Vida (1932), prologado por Juan Ramón Jiménez y donde realizó un viraje hacia la espiritual poética española, cuyo eje central giraría en torno a dimensiones como el amor o la soledad: Sintesis de las horas. / Tú y yo en movimiento / luchando vida a vida, / gozando cuerpo a cuerpo (MÉNDEZ CUESTA, 1979, p. 39)26. Es decir, deja atrás la experiencia transeúnte de la vanguardia y la modernidad para aterrizar frente a un nuevo escenario de cambios políticos y personales ${ }^{27}$.

Durante esta década la pareja prosiguió en su pequeña imprenta de exquisito sello editorial, de modo que encauzaron su aventura empresarial junto a la poética más creativa de ambos, entre España e Inglaterra, antes del estallido de la Guerra Civil y la pérdida de su primer hijo. En 1933 le fue concedida a Manuel Altolaguirre una beca de especialización editorial en Londres a través de la Junta de Ampliación de Estudios (1933-1935) y mediante esta nueva oportunidad ampliaron sus proyectos editoriales e intelectuales, al tiempo

\footnotetext{
25 "Navegar". Publicado originariamente en MÉNDEZ CUESTA, 1930.

26 "Recuerdo de sombras". Publicado originariamente en MÉNDEZ CUESTA, 1932.

27 Tres libros de poemas vieron la luz durante una segunda etapa en Concha Méndez donde irrumpe el primer exilio: Vida a vida. Prólogo de Juan Ramón Jiménez (Madrid, Ed. "La tentativa poética", 1932); Niño y sombras (Madrid, Ediciones Héroe, 1936) y Lluvias enlazadas. con retrato lírico de Juan Ramón Jiménez (La Habana, La Verónica, 1939) y con ello ya no quedaria rastro de la sonoridad del primer vanguardismo en los otros tres libros poéticos que le preceden. Un estudio pormenorizado de la obra y el contexto cultural de la escritora madrileña se halla en la documentada y amable lectura de la pionera investigación realizada por MARTiNEZ TRUFERO, 2011.
} 
que nace su hija Paloma Altolaguirre (Londres, 1935). Respecto a este periodo, Concha Méndez manifiesta en sus memorias el sacrificado trabajo encomendado pero concebido a su vez como un periodo fructífero, gracias a las primorosas creaciones editoriales de Altolaguirre y las contribuciones de ambos a la literatura española y extranjera. Es decir, los poetas no solo vieron ampliados sus compromisos editoriales, si no sus propias creaciones junto a la consolidación de nuevas relaciones intelectuales que luego amortiguarian la salida hacia exilio.

De estas experiencias profesionales y personales brota la quinta obra poética de Concha Méndez centrada en el desgarro que la asiste por la pérdida del primer hijo. Dos meses antes de estallar la guerra sale a la luz de la imprenta de la pareja, Niño y sombras (1936) cuyas estrofas vierten un pesimismo que será alentado de nuevo por el intimismo y la expresividad de su voz poética. De esta desigual confluencia emerge un dialogo donde tratara de trascender el peso de la muerte. Entre sus estrofas, la poeta transita del goce vivido a la angustia de la pérdida y la desafortunada soledad que presiente de su entorno, tras el nuevo quebranto y la fragilidad que por primera vez experimentará: Yo soy la vida en lucha / de cada hora y de cada paso. / Yo soy la fuerza de mi misma, / la antena receptora del milagro. / Yo soy la vida sin remedio (MÉNDEZ CUESTA, 1995, p. 103)28. En sintesis, tres libros de poemas conforman una segunda etapa en la que se incluye la experiencia del exilio y en cuyos versos no quedará rastro de la sonoridad del primer vanguardismo contenido en Inquietudes; Surtidor y Canciones de Mar y Tierra. Y no sólo despunta el dramatismo de una voz poética, tras las vivencias del hijo fallecido y la guerra civil, sino que irrumpe una voz depurada y personal que lograría asentar un ritmo propiamente singular.

Llegada la contienda, Concha Méndez transitó junto a su pequeña hija por Europa -Francia, Bélgica e Inglaterra-, para retornar a España a mediados de 1938 con el fin de reunirse con Altolaguirre. Decepcionada de la condición humana y apesadumbrada por la guerra tuvo que arropar al poeta ante el transitorio estado de locura tras su paso por el campo de concentración. A partir de este momento la familia comenzó su periplo, apoyada en su red intelectual, hacia América que les llevaria en palabras de María Zambrano a "amparar a los que tenían aún menos que ellos" (ULACIA ALTOLAGUIRRE, 2018, p. 8). El transtierro aminoró su sueño de poeta, cineasta y autora teatral, entre sus decantadas vocaciones creativas. Pero resistiendo a la tortuosa experiencia sobrevenida y al silencio recaído, la autora desafiaría, una vez más, este drama mediante el ritmo de sus versos: Soledad, yo te siento la mejor compañera; / en tus brazos me apoyo para ser cuanto quiero. / iAmparada en tu fuerza, puedo ser yo esa fuerza / que me lleve algún dia a habitar un lucero! (MÉNDEZ CUESTA, 1976, p. 99)²9. Asi transitaron en condiciones sacrificadas y extremas como exiliados en La Habana (1939-1943), donde Concha Méndez llegaria a recorrer las soporiferas calles de la capital antillana para vender las obras impresas de su rotativa editorial. En el exilio, publicó su sexta obra poética: Lluvias enlazadas (1939)30, cuyo ritmo se encuentra pautado por un desasosegado y enajenado periodo:
Quisiera tener varias sonrisas de recambio
y un vasto repertorio de modos de expresarme. O bien con la palabra, o bien con la manera, buscar el hábil gesto que pudiera escudarme... $Y$ al igual que en el gesto buscar en la mentira diferentes disfraces, bien vestir el engaño; y poder, sin conciencia, ir haciendo a las gentes, con sutil maniobra, la caricia del daño.
Yo quisiera iy no puedo! ser como son los otros, los que pueblan el mundo y se llaman humanos: siempre el beso en el labio, ocultando los hechos
y al final... el lavarse tan tranquilos las manos (MÉNDEZ CUESTA, 1976, p. 78) 31. $^{1}$

\footnotetext{
28 "Fuerzas ocultas me sostienen". Originalmente publicado en MÉNDEZ, 1936.

29 "Soledad". Originalmente publicado en MÉNDEZ, 1944

30 Asimismo, edita en La Verónica dos piezas teatrales: El solitario (1941) y una segunda edición de El carbón y la Rosa (1942), mientras que La caña y el tabaco: Alegoria antillana (1942), permaneceria inédito (VALANDER, 2001, pp. 51-52).

31 "Quisiera tener". Originalmente publicado en MÉNDEZ CUESTA, La Habana, 1939 (escrito en Bruselas en 1937).
} 
En 1943 Altaloguirre y Méndez abandonaron definitivamente, junto a su hija, La Habana para asentarse en Ciudad de México que era su destino inicial tras la contienda. En el exilio mexicano prosiguieron su trayectoria profesional y personal, a un mismo tiempo pero en distintas direcciones, puesto que un año después de su llegada la pareja se separaría (1944). Ese mismo año y tras un breve contacto con poetas y editoras mexicanas, alentada principalmente por la revista Rueca, dio a conocer algunos de los versos de Sombras y sueños (1944): Alma mía, ¿a dónde vas caminando tan aprisa / por campos de soledad? / A dónde vas ¿di? ¿qué sueño / te espera en algún lugar / donde mis ojos no alcanzan /por más que quieren mirar? (MÉNDEZ CUESTA, 1976, p 91)32 que dan fe del tono y los elementos que configuraban la voz poética de ese instante. Entre estos despunta la nostalgia, la ausencia, la fragilidad, el tránsito de su nuevo designio por venir y la incertidumbre del proyecto de vida que sorteó durante el que sería su lugar en el mundo, es decir, el exilio: Ser agua, que sobre espejos / corriendo va hacia su fin, / arrastrando en su corriente blancos sueños de jazmin. / (...) Ser alma, dejando al cuerpo / dormido en algún lugar (MENDEZ CUESTA, 1995, p. 137)33. Desde esa fecha aconteció para la poeta un retraimiento público prolongado y acompasado con la postergación de su vasta obra, al tiempo que fue imprimiendo en su escritura nuevas cadencias con un remanente espiritual, en proyección al no lugar y a las luces y sombras que habita el transtierro (ZAMBRANO, 1943; GAOS, 1949; AUGÉ, 2001): Por la puerta del sueño / salgo a encontrarme, / cuando la vida quiere acorralarme (MÉNDEZ CUESTA, 1995, p. 208)34. Aun asi, continúo proyectándose en una tercera y última etapa poética durante el exilio que ha sido quizás el periodo menos estudiado de la poeta (1967-1986). Desde su espíritu vocacional recompuso un libro para niños, Villancicos de Navidad (1944.) y tres reflexivos libros de poemas donde retornaria al pasado, bajo el recurso de la remi- niscencia: Vida o rio (1944), Entre el soñar y el vivir (1981) y Con el alma en vilo (1986). Su voz poética se introduce de nuevo en las sombras, oscilante entre el sueño y la vigilia en combinación con la fantasía de elementos de la naturaleza a los que ya había recurrido en su primera etapa. Solo asi pareciera amortiguar los anhelos cercenados y proyectados, entre la rebeldía y la contención a lo establecido que resistió desde su propia y autónoma identidad.

En sintesis, las contradicciones aparejadas al progreso y la modernidad de los años veinte y treinta trataron de ser reajustadas en clave de equidad cuyo punto de inflexión se alcanza con el reformismo republicano. En una conservadora y jerárquica sociedad -donde las mujeres se hallaban vigiladas por la institución eclesiástica, reprendidas por la moral religiosa e indefensas frente a un aparato juridico que las desamparaba- se desplegaron acciones y propuestas de continuidad feministas. Impulsadas por instituciones y foros feministas, las oportunidades de conquistar espacios públicos lograrian parcelas de autonomía y emancipación personal, al tiempo que contravenian la autoridad patriarcal. Sin embargo, aun erigiéndose en un lento y confrontado movimiento de distinto signo al sufragista de estilo anglosajón, será la instrucción, la promoción educativa como las mejoras laborales las premisas centrales en las organizaciones tanto progresistas como conservadoras españolas, puesto que los valores de la cultura de masas, la industrialización, los cambios en el planeamiento urbanístico y el desarrollo de la mecánica y la técnica proscribian a las féminas a los subterfugios del progreso. Por un lado, las obreras subsistian en un estado de esclavitud bajo el desamparo socio jurídico y la barbarie del capitalismo patriarcal. Por otro lado, la aspiración a la formación, al conocimiento y el acceso de las mujeres a las esferas artístico culturales con-

\footnotetext{
"Alma mia". Originalmente publicado en MÉNDEZ CUESTA, 1944 
travenía los valores del paternalismo. A cambio hubieron de sortear la condescendencia y, en su caso, la hostilidad intelectual, mientras que estrictos códigos morales y pautas de decoro decimonónicos las clasificaba entre mujeres malas y mujeres buenas.

Más allá de los simbolos formalistas, singularizados en la imagen de la nueva mujer: moderna, liberada en la toma de decisiones, ataviada con nuevos gustos estéticos para la condición mejor posicionada, etc., cotas emancipatorias se fraguaron a través de la re-significación de los espacios dicotómicos, naturalizados en razón al sexo. En este sentido, las reformas políticas canalizaron propuestas interclasistas de cambio social que llevaban aparejado el rechazo a la ideología de la domesticidad con el fin de superar tanto los márgenes como la exclusión a las que asistian las féminas de distinto estatus, si bien su materialización última requería de cambios estructurales y apoyos logísticos para un desarrollo de autonomía plena. No obstante, la categoria de sujetos y de ciudadanía fue encauzada mediante la obtención de derechos políticos entre ellos la consecución del voto femenino, el matrimonio civil y el divorcio, mientras que las reformas del sistema educativo, la concepción de la familia, la protección de la maternidad y la sexualidad fueron igualmente promovidas a tenor de la constitución republicana pero catapultadas tras el largo invierno franquista.

En su caso, Concha Méndez despuntó en el campo de las artes y las letras al mismo tiempo que contravenía el arquetipo de género y la condición de clase a la que estaba predestinada desde la cuna. Es decir que entre habitar el rol de musa y/o ángel del hogar acabó por apostillar a una visibilidad social e intelectual desde el discurso explorativo como experimental de la modernidad en el marco de su grupo intelectual. Nacida en el seno de una familia numerosa acomodada destacó durante su juventud en la práctica del deporte, en cuanto a signo de modernidad, mediante el cual obtuvo premios de natación alentada por los veranos de placer en la costa norte española. Un pódium dado a conocer por la prensa y entre los ecos de la sociedad bajo un discurso almibarado de sus gustos por la escritura y las artes. Embriagada por los aires de la modernidad y de las vanguardias artísticas, dentro del urbano fulgory del cosmopolitismo madrileño, Concha Méndez sostuvo la convicción de una vocación en un ámbito adscrito a los varones, tal como era la esfera de la cultura y las letras. Exploró diversas claves narrativas que oscilaban entre el clasicismo y la modernidad -sobresaliendo en la lírica- hasta anclarse en un desarrollo creativo personal, sostenido entre 1934 y 1944 pero menguado tras un silenciado exilio y replegado, en mayor medida, al espacio privado. Un periodo, el del transtierro y silenciamiento mexicano, que aún requiere de un estudio pormenorizado comparativamente al explorado durante la pre-guerra y el primer exilio.

Las diferencias y las desigualdades de diverso signo adoptaron una pronta toma de conciencia en la escritora madrileña que la llevó amparar un firme compromiso humanistico. Singularizada por una autónoma y desenvuelta personalidad, muy moderna a su tiempo, trascendió la autoridad patriarcal mediante algunos transgresores y no menos estrambóticos episodios: hechos narrados en unas memorias dictadas y transferidas de manera seleccionada por su nieta. Reafirmada en su personalidad emancipadora logró alcanzar un desarrollo creativo, aunque escindido bajo las circunstancias que le tocó en suerte sortear, mientras que su trotamunda sociabilidad quedaba fortalecida por su moderna vigorosidad, tal como se extrae de los solitarios y redentores viajes por el extranjero como por su resolutiva proyección en el exilio. El retorno de su primera experiencia en el extranjero vino a coincidir con la promulgación de la República y su matrimonio con al poeta y editor Manuel Altolaguirre. El misterio, el cosmos de los sueños y la vigila configuraron su imaginario cultural y perfilaron su identidad, tal como se refleja en el locuaz relato oral de sus memorias, en cuanto a ejercicio evocativo, y donde Maria Zambrano ya testimoniaba la apreciable inventiva y el arte supremo que habitaba en todos los proyectos emprendidos por Concha Méndez junto a Manuel 
Altolaguirre (ULACIA ALTOLAGUIRRE, p. 7). Para ser tomada en serio como portavoz de la vida de los otros ((ULACIA ALTOLAGUIRRE, p. 20). Sea como fuere, y a pesar de haber sido destacada por el rol de compañera, amiga, novia y/o esposa de creadores e intelectuales relevantes, Concepción Josefa Pantaleona Méndez cuarteó la autoridad patriarcal -el pacto patriarcal interclasista- reforzada por un firme desarrollo autónomo y por una capacidad de sostenerse en su vocación intelectual y su propio imaginario poético diseminado entre España y América.

\section{Referencias}

AGUILERA, Juan. Las fundadoras del Lyceum Club femenino español. BROCAR: Cuadernos de Investigación Histórica, n. 35, p. 65-90, 2011. Disponible en: https:// publicaciones.unirioja.es/ojs/index.php/brocar/article/view/1595/0. https://doi.org/10.18172/brocar.1595

AGUADO, Ana y RAMOS, Maria Dolores. La modernización de España (1917-1939). Madrid: Editorial Sintesis, 2002.

AGUADO, Ana M. y ORTEGA LÓPEZ, Teresa María (coord.). Feminismos y antifeminismos: culturas políticas e identidades de género en la España del siglo XX. Valencia: Universitat de València, 2011.

AMORÓS, Celia. Violencia contra las mujeres y pactos patriarcales. In: MAQUIEIRA, Virginia y SÁNCHEZ, Cristina (comp.). Violencia y sociedad patriarcal. Madrid: Ed. Pablo Iglesias, 1990. p. 1-15.

AUGÉ, Marc. Los no lugares. Barcelona: Gedisa, 2001.

BALLÓ, Tánia. Las Sinsombrero. Madrid: Espasa, 2016.

BELLVER, Catherine G. Exile and the Female Experience in the Poetry of Concha Méndez. Anales de Literatura española contemporánea, Universidad de Alicante, n. 18, p. 27-42, 1993.

Literary Influence and Female Creativity: The Case of Two Women Poets of the Generation of 27. Siglo XX, Universidad de Valladolid, n. 15, p.7-32, 1997.

Los exilios y las sombras. In: VALANDER, James. Una mujer moderna. Concha Méndez en su mundo (18981976). Madrid: Residencia de Estudiantes, 2001, pp. 63-72.

BIZCARRONDO, Marta. Los origenes del feminismo socialista en España. In:

BLASCO, Inmaculada. Paradojas de la ortodoxia. Política de masa y militancia femenina en España (1919-1939). Zaragoza: Prensas Universitarias de Zaragoza, 2003. Disponible en: https://core.ac.uk/download/pdf/290003355. pdf. https://doi.org/10.26754/uz.84-7733-633-4

CAPMANY, Aurelia. El feminismo ibérico. Barcelona: Oikos-Tau, 1970.
CASTILLO, Marcia. Las convidadas de papel: mujer, memoria y literatura en la España de los años veinte. Madrid: Ayuntamiento Alcalá de Henares, 2001.

EIROA, Matilde. El Lyceum Club: cultura, feminismo y política fuera de las aulas. In: coord. por Josefina, CUESTA BUSTILLO, Josefina, et. al. La residencia de señoritas y otras redes culturales femeninas. Universidad de Salamanca, Ediciones Universidad de Salamanca: Fundación José Ortega y Gasset, 2015. 197-226.

FAGOAGA, Concha. La voz y el voto de las mujeres: el sufragio en España 1877-1931. Barcelona: Icaria, 1985.

- El Lyceum Club de Madrid, élite latente. In: BUSSY, Daniéle (ed.). Les Espagnoles dans l'histoire: une sociabilité démocratique (XIX-XX siecles). Saint-Denis: Presses Universitaires de Vincennes, 2002. 145-67.

FOLGUERA, Pilar (coord.). La mujer en la Historia de España (siglos XVI-XX). Actas de las II Jornadas de Investigación Interdisciplinaria, Madrid: SEM de la UAM, 1984. 137-158.

FOLGUERA, Pilar (coord.). El feminismo en España. Madrid: Fundación Pablo Iglesias, 1988.

GAOS, José. Los 'transterrados' españoles de la filosofía en México, Filosofia y Letras, n. 36, 207-231. 1949.

Confesiones de transterrado. Universidad de México, n. 521, p. 3-9. 1994.

GIMÉNEZ CABALLERO, Ernesto. Las mujeres de Cogul. La Gaceta Literaria, n.122, Madrid, 15 de febrero de 1932.

GÓMEZ BLESA, Mercedes. Modernas y Vanguardistas: las mujeres-Faro de la Edad de Plata. Madrid: Ed. Huso, 2019.

GÓMEZ DE LA SERNA, Ramón. En, por, sin, sobre el sinsombrerismo. El Sol, n. 4.067. Año XIV, 1930.

HURTADO, Amparo. El Lyceum Club Femenino (Madrid 1926-1939). Boletín de la Institución Libre de Enseñanza, Madrid, n. 36, p. 23-36, 1999. Disponible em: http:// WWW.nadieseacuerdadenosotras.org/WEB_SECCIONES_14_8_10/MOVIMIENTOS_FEMINISTAS_MILICIANAS_II\%20REPU/PDF_FEMINSIMOS_REPUBLICA/ El_Lyceum_Club_de_Madrid_un_refugio_feminista_ en_una_capital_hostil.pdf.

ITURRALDE, Gamito. Concha Méndez, del Lyceum Club: campeona de natación y poetisa. El Diario Alavés, Vitoria, 1928.

KIRKPATRICK, Susan. Mujer, modernismo y vanguardia en España (1898-1931). Madrid: Cátedra, 2003.

LUENGO LÓPEZ, Jordi. María de la O Lejárraga en Blanco y Negro: columnas, cartas y calendarios ante el advenimiento de la mujer moderna. Revista de Escritoras Ibéricas, Madrid: UNED, n. 4, p. 121-152, 2016. Disponible en: http://revistas.uned.es/index.php/REl/article/ view/17150. https://doi.org/10.5944/rei.vol.4.2016.17150

LLONA GONZÁLEZ, Miren. El feminismo católico en los años veinte y sus antecedentes ideológicos. Vasconia: Cuadernos de Historia - Geografia, n. 25, 283-299, 1998. Disponible en: https://core.ac.uk/download/pdf/11496468.pdf. 
MANGINI, Shirley. El Lyceum Club de Madrid un refugio feminista en una capital hostil. Asparkia, Castellón, n. 17. p. 125-140, 2006. Disponible en: https://www.e-revistes. uji.es/index.php/asparkia/article/view/496

Las modernas de Madrid: las grandes intelectuales españolas de la vanguardia. Madrid: Ed. Peninsula, 2001.

MAINER, José Carlos. Un paseo por el 'barrio laico'. Revista Claves de Razón Práctica, Madrid, n. 241, p. 160-167. 2015. Disponible em: https://www.elboomeran.com/ upload/ficheros/noticias/10.12_sembnzmainer8nxa.pdf.

MARCOS DEL OLMO, Cristina y SERRANO GARCIA, Rafael (eds.). Mujer y politica en la España contemporánea (1868-1939). Valladolid: Universidad de Valladolid, 2012.

MARINA, José Antonio y RODRIGUEZ, María Teresa de. La conspiración de las lectoras. Barcelona: Anagrama, 2009.

MARTÍNEZ TRUFERO, Begoña. La construcción identitaria de una poeta del 27. Concha Méndez Cuesta (18981986). 2011. Tesis doctoral (Filología Hispánica). Universidad Nacional de Educación a Distancia, Madrid, 2011.

MARTINEZ SIERRA, Gregorio. Cartas a las mujeres de España. Madrid: Renacimiento, 1930.

MARTÍNEZ, Cándida (dir.). Mujeres en la historia de España: enciclopedia biográfica. Barcelona: Planeta, 2000.

MATILLA QUIZA, María Jesús. María Lejárraga y el asociacionismo femenino. 1900-1930. In: AGUILERA SASTRE, Juan. Maria Martínez Sierra y la República: ilusión y compromiso: II Jornadas sobre Maria Lejárraga. Logroño: Instituto de Estudios Riojanos, 2001, p. 83-101.

MÉNDEZ CUESTA, Concha. Inquietudes. Madrid: Imprenta de Juan Pueyo, 1926.

Surtidor. Madrid: Imprenta Argis, 1928.

. Canciones de Mary Tierra. Buenos Aires: Talleres Gráficos Argentinos L. J. Rosso, 1930.

Vida a vida. Prólogo de Juan Ramón Jiménez. Madrid: Ed. La Tentativa Poética, 1932.

Niño y sombras. Madrid: Ediciones Héroe, 1936.

Lluvias enlazadas: con un retrato lírico de Juan Ramón Jiménez. La Habana: La Verónica, 1939.

Poemas. Sombras y sueños. México D. F.: Ed. Rueca, 1944

Villancicos de Navidad. México D. F.: Ed. Rueca, 1944.

Vida a vida y Vida o Río: Concha Méndez (prelim. EmiLio Miró). Madrid: Ed. Caballo griego para la poesía, 1979).

Antología Poética. México: Joaquín Mortiz, 1976.

Poemas (1926-1986): introducción y selección de James Valender. Dibujos de Norah Borges, Gregorio Prieto y Manuel Altolaguirre, Madrid: Ediciones Hiperión, 1995

MILLET, Kate. Politica Sexual. México: Aguilar 1975.

MORCILLO GÓMEZ, Aurora. Españolas: femenino/ mismo plural (1900-1940). In:
MUÑOZ CÁLIZ, Berta. Infancia y exilio: el teatro de Concha Méndez. In: AZNAR SOLER, Manuel (coord.). La literatura dramática del exilio republicano de 1939. vol. 1. Sevilla: Renacimiento, 2018, pp. 187-200.

NASH, Mary. Mujer y movimiento obrero en España, 1931-1939 Barcelona: Fontamara, 1981.

Rojas: las mujeres en la Guerra Civil, Madrid Taurus, 1999

Experiencia y aprendizaje: la formación histórica de los feminismos en España, Historia Social, n. 20 , 151-172, 1994.

NELKEN, Margarita. La condición social de la mujer en España. Barcelona: Minerva, 1919.

La mujer ante las Cortes Constituyente: Madrid: Castro, 1931

NIEVA DE LA PAZ, Pilar. La memoria del teatro en la narrativa de las escritoras españolas exiliadas. Anales de la literatura española contemporánea. Philadelphia, vol. 29, n. 2, 63-91, 2004.

Concha Méndez y Manuel Altolaguirre: la memoria de una vocación teatral. Anales de la literatura española contemporánea. Philadelphia, vol. 38, n. 3, 257283, 2013. http://digital.csic.es/handle/10261/129412.

- Las escritoras españolas en el teatro infantil de preguerrra: Magda Donato, Elena Fortún y Concha Méndez. Revista de Literatura, Madrid, n. 109, 113-129, 1993.

Exilio, tradición y vanguardia: la caña y el tabaco (1942) de Concha Méndez. In: FERNÁNDEZ, Antonio, et. al, Setenta años después: el exilio literario español de 1939, Oviedo: KRK, 2010, pp. 443-458

NÚÑEZ, Maria Gloria. Políticas de igualdad entre varones y mujeres en la Segunda República. Espacio, Tiempo y Forma. Historia contemporánea, Madrid, serie V, n.11, 393-446, 1998. Disponible en: http://revistas.uned.es/ index.php/ETFV/article/view/2957/2817. https://doi. org/10.5944/etfv.11.1998.2957.

PÉREZ DE AYALA, Juan. Historia de un taxi (1927). La aventura cinematográfica de Concha Méndez. Revista de Occidente, n. 211, 115-128, 1998

POZO, Ma del Mar. Actividades culturales y pedagógicas del Lyceum Club Femenino de Madrid (1926-1936). In: RUIZ BERRIO, Julio (ed.). La educación en la España contemporánea: cuestiones históricas. Madrid: Sociedad española de pedagogía, 1985. 203-212.

QUANCE, Roberta. Hacia una mujer nueva. In VALANDER, James (ed.). Una mujer moderna. Concha Méndez y su mundo (1898-1986). Madrid: Publicaciones de la Residencia de Estudiantes, 2001, pp. 103-113.

RAMOS, Maria Dolores. Identidad de Género, feminismo y movimientos sociales en España. Historia contemporánea, Universidad del País Vasco, n. 21, 523-552, 2000.

Identidad de género, feminismo y movimientos sociales en España. Historia Contemporánea, Universidad del País Vasco, n. 21, 523-552, 2002. https://ojs. ehu.eus/index.php/HC/article/view/15908/13818. 
(ed.). República y republicanas en España. Madrid: Marcial Pons, 2006

(coord.). Tejedoras de Ciudadania: culturas politicas, feminismos y luchas democráticas en España. Málaga: Universidad de Málaga, 2014.

RODIGO MORA, Félix, Investigación sobre la Il República Española, 1931-1936. Madrid: Potlatch Ediciones, 2016.

RODRIGO, Antonina. Isabel Oyarzábal de Palencia: primera mujer embajadora de la República. Actas del congreso internacional: El exilio literario español de 1939. vol. 1. Barcelona: Gexel, 1998. 68-81. Disponible en: https:// journals.openedition.org/bulletinhispanique/3252. https://doi.org/10.4000/bulletinhispanique.3252.

RUBIO, Oliva Maria y TEJEDA, Isabel (dirs.). 100 años en femenino: una historia de las mujeres en España. Madrid: Acción Cultural Española, 2012.

RUBIO, Oliva Maria y TEJEDA MARTíN, Isabel (coord.). 100 años en femenino: una historia de las mujeres en España. Madrid: Centro Conde Duque de Olivares, 2012. 52-77.

SANFELIU, Luz. La enseñanza de lo público. el asociacionismo feminista progresista durante la II República. Historia Social, Valencia, n. 82, 149-166, 2015. Disponible en: https://www.jstor.org/stable/43867466? seq=1.

ULACIA ALTOLAGUIRRE, Paloma. Concha Méndez: memorias habladas, memorias armadas. Sevilla. Renacimiento, 2018.

UTRERA MACIAS, Rafael. Film Dalp Nazarí: productoras andaluzas. Granada: Manigua, 2000.

VALANDER, James. Concha Méndez en el Río de la Plata (1929-1931). In: VALANDER, (ed.). Una mujer moderna: Concha Méndez y su mundo (1898-1986). Madrid: Publicaciones de la Residencia de Estudiantes, 2001, pp. 149-163.

Campeona de natación y poetisa. Concha Méndez, del Lyceum Club, El Diario Alavés [Vitoria], 12, 1928. In: VALENDER, James (ed.). Concha Méndez en su mundo (1898-1986), Madrid: Residencia de Estudiantes, 2001, pp. 33-38.

(ed.). Manuel Altolaguirre y Concha Méndez: poetas e impresores. Madrid: Publicaciones Residencia de Estudiantes, 2001

ZAMBRANO, María. La confesión: género literario y método. México, Ediciones Luminar, 1943.

\section{Esmeralda Broullón-Acuña}

Doutora em História pela Universidade de Cádiz (UCA), Andalucía, España; Científica Titular em la Escuela de Estudios Hispano-Amaericanos del Consejo Superior de Investigación Científica en Sevilla (EEHA- CSIC), Andalucía. España

\section{Dirección:}

Esmeralda Broullón-Acuña

Escuela de Estudios Hispano-Americanos

Calle Alfonso XII, n 16, 41002

Sevilla, España 